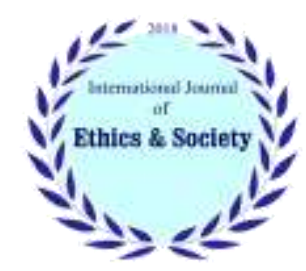

International Journal of Ethics \& Society (IJES)

Journal homepage: www.ijethics.com

Vol. 3, No. 4 (2022)

(Original article)

\title{
Predicting the Psychological Empowerment of Faculty Members Based on the Spiritual Leadership Model
}

\author{
Esmail Yosefi ${ }^{a}$, Morteza Samiee Zafarghandi ${ }^{*}$, Zahra Taleb $^{c}$ \\ a) Ph.D. student in Educational Management, South Tebran Branch, Islamic Arad University, Tebran, Iran \\ b) Dept. of Educational Management, Research Institute of the Ministry of Education, Tehran, Iran \\ c) Dept. of Educational Management, South Tehran Branch, Islamic Azad University, Tehran, Iran
}

\begin{abstract}
Background: Academic faculty members of universities are the main element of science transfer and development of societies whose empowerment is an inevitable necessity. Therefore, the main purpose of this study was to predict the psychological empowerment of employees based on the model of spiritual leadership.

Method: The method of the present study was descriptive-correlational in terms of implementation method and applied in terms of purpose. The statistical population of the study was 162 professors and lecturers of Farhangian University of Isfahan in 2009-2010. Based on Morgan and Krejcie (1970) table, 110 of them were selected by simple random sampling method. The research instruments were the standard questionnaires of Fry Spiritual Leadership (2005) and Spreitzer Job Empowerment (1995), the reliability of which was obtained by Cronbach's alpha test of 0.89 . Pearson correlation test with SPSS23 software and structural equation approach with Amos20 software were used to analyze the data.

Results: Data analysis showed that spiritual leadership has a significant relationship with psychological empowerment of employees $(r=0.44$ and $\mathrm{P}<0.01)$. Spiritual leadership also predicts 0.45 variance of variable psychological empowerment of Farhangian University faculty members. Among the dimensions of spiritual leadership, perspective (0.83), altruism (0.81) and faith and hope (0.80) had the highest path coefficient on empowerment, respectively.

Conclusion: Considering the effect of spiritual leadership on the psychological empowerment of faculty members, it is necessary to review the patterns of leadership in cultural universities and the appointment of individuals as the president of universities should be done more with the style of spiritual leadership.
\end{abstract}

Keywords: Empowerment, Spiritual leadership, Altruism

*Corresponding Author: Email: mo_samie@yahoo.com

Received: 10 Aug 2021

Accepted: 07 Sep 2021

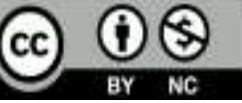

Copyright: (C) 2022 Samiee Zafarghandi M. et al. Published by Iranian Association of Ethics in Science and Technology This article is an open access article distributed under a Creative Commons Attribution-Noncommercial 4.0 International License. (https://creativecommons.org/licenses/by-nc/4.0/ ).

16

Available at: www.ijethics.com 


\section{Introduction}

Professors and faculty members are an important element of the university. Faculty members have the ability to direct their organization toward an interactive environment or organizational weakness. In fact, their ability is so important that this issue leads to growth or in case of weakness, inefficiency of the university administration (1). They must be able to perceive changes in the environment in favor of the university, use teaching-learning processes appropriate to the students' circumstances, keep their students active and dynamic, and, on the other hand, have effective relationships with their peers (2). The realization of these processes requires the empowerment of teachers as educational staff (3).

There are many definitions of empowerment. Some believe that the main element of empowerment is to empower employees in relation to specific tasks and define empowerment as the transfer of power from the employer to employees to make decisions quickly (4). Psychological empowerment as a new approach to job motivation means releasing employees' internal forces and providing contexts and opportunities for individuals to develop their talents, abilities, and competencies (5). There are two different approaches to empowerment. The first approach is called the communication approach, which emphasizes environmental elements and defines empowerment as a set of managerial activities that give employees power, control, and authority (6). Proponents of this view see the concept of empowerment as an effort to increase levels of employee participation in the decision-making process, which encourages employees to be more actively involved throughout the organization (7). The second approach arises from employees' perceptions. This approach emphasizes the concept of psychological empowerment. This approach points to whether or not employees feel empowered (8). Employee empowerment has four main components. 1- Meaning in work; Refers to the value of work goals based on judgments about one's ideals and criteria. It is also a person's inner interest in work and includes the fit between the work require- ments, values and beliefs of the person. 2- Competence; Refers to the degree to which a person feels capable of performing professional tasks with skill. 3-Independence; A sense of independence at the beginning of activities and systematization of work is a reflection of the degree of freedom of action in work behaviors and processes, and they can decide for themselves the process of doing their work. Thomas \& Velthouse define autonomy as having the right to choose. 4- To be effective; It is the degree to which one feels one can influence the strategic, administrative, or operational consequences of the job (8).

One of the important factors in employee empowerment is leadership styles (9). Spiritual leadership is one of the leadership styles that enhances employee empowerment (10). Spiritual leadership includes the values, attitudes, and behaviors that are needed to motivate oneself and others to experience spiritual survival through duty and membership, and includes religious, moral, and value-based approaches to leadership. Spiritual leadership is also manifested through behavior, in one's thoughtful action, or in the moral, compassionate, and respectful behavior of others (11). Spiritual leadership also helps employees understand the true meaning of their job and care about their responsibilities. It also gives them the feeling that their job is important to the organization and other partners (12). Spiritual leadership is a causal theory for organizational change and spontaneous organizational creation. This theory is based on the model of intrinsic motivation, which combines insight, faith and hope, love of altruism, spirituality of the workplace, and spiritual happiness and survival (13). In fact, spirituality in the workplace describes the experience of employees whose work is satisfying, meaningful and purposeful. Experience spirituality in the workplace is also associated with increased creativity, satisfaction, honesty, trust and commitment at work (14). Accordingly, the main goal in spiritual leadership is to acquire the vision and core values for the organization in order to empower employees for the growth and excellence of the organization and healthy competition with other organizations (15). 
Some scholars have suggested seven dimensions for spiritual leadership; 1) A vision that includes the image of the group and the group. 2) Love of the same kind: Love of others means a set of values, assumptions, and ways of thinking that are morally correct and shared by group members and taught to new members. 3) Membership, which is a sense of understanding and appreciation, and to a large extent, interaction and communication is created through social interaction and membership in groups. 4) Hope - Faith: A firm belief in something for which there is no proof and physical and material evidence has not proved its existence. 5) Meaningful: It means that employees have a sense of importance of their work and that performing the duties of each one is socially and individually meaningful for the individual. 6) Organizational commitment: Organizational commitment is an attitude and a mental state that indicates the desire, need and obligation to continue operating in an organization. 7) Continuous empowerment: Continuous improvement means that with innovation and creativity, new ways and high capabilities can be created (16).

Employee empowerment studies have focused especially on manufacturing and industrial organizations and companies, but are scarce in educational and scientific organizations. In a study of four dimensions of spiritual leadership (relationship with God, relationship with others, relationship with self, and work motivation) with the organizational empowerment of the police has been a significant relationship (17). In a study, spiritual leadership had a positive and significant correlation with employee empowerment (18). In a study, researchers analyzed the effect of spiritual leadership dimensions and its consequences on organizational performance empowerment and concluded that spiritual leadership has a positive and significant effect on organizational performance empowerment (14). Other researchers have concluded that the dimensions of spiritual leadership (significance at work, organizational commitment, organizational perspective, faith in work) are directly related to empowerment (19). In another study, it was shown that spiritual leadership is significantly related to psychological empowerment of employees (20). Other researchers have concluded that spiritual leadership has a significant relationship with different levels of empowerment and its consequences such as work performance and knowledge sharing and creativity of employees (21). In another study, it was shown that there is a significant relationship between managers' spiritual leadership style and sense of competence, sense of independence and sense of efficiency (22). Researchers in another study showed that ethical (spiritual) leadership is associated with leader-member exchange, self-efficacy and organizational identity, and thus affects employee performance (23).

Spiritual leadership in educational organizations consists of two pillars. First, creating a vision in which members of the educational organization feel an invitation in which their lives find meaning and make a difference. Second, the creation of a socio-organizational culture based on love and philanthropy in which leaders and followers express genuine interest and gratitude both to themselves and to others, thereby forming a sense of membership and a sense of understanding and appreciation (24). In this regard, Farhangian University is part of the higher education system, which is directly responsible for providing manpower for education. Undoubtedly, the leadership and administration of these universities have a great impact on various aspects of professors' capabilities and their output. The leadership relationship in this university is very important in that if the professors of these universities have the desired level of ability, we can hope to train qualified human resources (teachers) because the product of Farhangian University is used directly in education.

The innovation of the present study is that in Farhangan University, there are few researches that have dealt with the issue of empowering professors and a research gap has been created. The results of the research can lead to increasing knowledge about the empowerment of faculty members and use the results for better management of leadership in Farhangian University. Accordingly, the main purpose of this study is to predict the psychological empowerment of faculty members based on spiritual leadership in Farhangian University. 


\section{Material \& Methods}

The method of the present study was descriptivecorrelational and applied in terms of purpose. The statistical population of all professors in different fields of the two campus centers (girls and boys) was 162 that the sample size was determined based on Morgan and Krejcie table of 110 people (Table 1). Simple random sampling method was used to determine the sample.

The research tool includes the following questionnaires: 1- Spiritual leadership in the university (2005). The Spiritual Leadership Questionnaire was developed by Fry et al. This questionnaire has 7 components (vision, love of altruism, faith, significance, membership, organizational commitment and continuous feedback) and 25 items that according to the Likert scale, strongly disagree (1), disagree (2), have no opinion (3), Agree (4) and strongly agree (5) will be ranked. A score range among 25 to 58 indicates low spiritual leadership, between 92-59 indicates moderate, and between 125-93 indicates high spiritual leadership. In one study (25) the reliability of this instrument was obtained by Cronbach's alpha test (0.96) and in another study the value was 0.91 (16).

2- Job Empowerment Questionnaire: This questionnaire was prepared by Spreitzer (1995) and has 5 components (meaningfulness, competence, independence and autonomy and effectiveness) and 15 items with a range of five Likert options (strongly disagree (1), disagree (2), I have no opinion (3), I agree (4) and I completely agree (5) The reliability of this questionnaire has been reported by its creator as 0.88 .

Correlation tests in SPSS-23 software and structural equation approach with Amos20 software were used to analyze the data.

Table 1. Profile of respondents (gender, education, age and academic rank)

\begin{tabular}{|c|c|c|c|}
\hline Variable & Factors & Frequency & Percentage \\
\hline \multirow[t]{2}{*}{ Gender } & Male & 79 & 81.81 \\
\hline & Female & 31 & 28.18 \\
\hline \multirow[t]{2}{*}{ Education } & M.A & 34 & 30.90 \\
\hline & Ph.D. & 76 & 69.10 \\
\hline \multirow[t]{4}{*}{ Age } & $30-40$ & 29 & 26.36 \\
\hline & $41-50$ & 39 & 35.45 \\
\hline & $51-60$ & 31 & 28.18 \\
\hline & More than 60 & 11 & 10 \\
\hline \multirow[t]{5}{*}{$\begin{array}{l}\text { Scientific } \\
\text { rank }\end{array}$} & $\begin{array}{l}\text { Invited } \\
\text { teachers }\end{array}$ & 28 & 25.45 \\
\hline & Teacher & 33 & 30 \\
\hline & Assistant & 24 & 21.92 \\
\hline & Associate & 15 & 13.63 \\
\hline & Professor & 10 & 9 \\
\hline
\end{tabular}

\section{Results}

Prior to correlation between the variables, the normality distribution of the data was performed by the Kolmogorov-Smirnov test and is reported in Table (2).

Table 2. Kolmogorov-Smirnov test results

\begin{tabular}{|c|c|c|c|c|c|}
\hline \multirow{2}{*}{$\begin{array}{c}\text { Variables } \\
\text { Skewness }\end{array}$ Kurtosis } & $\begin{array}{c}\text { Kolmogorov } \\
\text { value }\end{array}$ & 0.96 & 0.495 & Normal \\
\hline Spiritual leadership & 0.98 & 0.9 & 0.84 & 0.372 & Normal \\
\hline Vision & 0.03 & 0.91 & 0.93 & 0.459 & Normal \\
\hline Altruism love & 0.95 & 0.51 & 0.89 & 0.421 & Normal \\
\hline Faith and hope & 0.41 & 0.28 & 0.97 & 0.501 & Normal \\
\hline Meaningful & 0.51 & 0.17 & 0.82 & 0.356 & Normal \\
\hline Membership & 0.36 & 0.06 & 0.8 & 0.333 & Normal \\
\hline Organizational commit- & 0.07 & 0.66 & 0.94 & 0.468 & Normal \\
\hline ment & & & 0.91 & 0.439 & Normal \\
\hline Function & 0.03 & 0.03 & 0.87 & 0.404 & Normal \\
\hline Empowerment & 0.6 & 0.77 & 0.88 & 0.413 & Normal \\
\hline To make sense & 0.47 & 0.38 & 0.9 & 0.43 & Normal \\
\hline Competence & 0.55 & 0.91 & 0.97 & 0.5 & Normal \\
\hline Independence & 0.62 & 0.93 & & &
\end{tabular}


The results of Table (2) show that the research variables have a normal distribution $(\mathrm{P}<0.05)$. Therefore, parametric tests can be used. The correlation of the dimensions of the variables is shown in $\mathrm{Ta}$ ble (3).

Table 3. Correlation matrix of spiritual leadership dimensions with empowerment

\begin{tabular}{|l|l|l|}
\hline \multicolumn{1}{|l}{$\begin{array}{l}\text { Relationship between empower- } \\
\text { ment and Spiritual leadership }\end{array}$} & \multicolumn{1}{l}{$\begin{array}{l}\text { Pearson } \\
\text { Coefficient }\end{array}$} & Sig. \\
\hline Vision & 0.35 & 0.009 \\
\hline Altruism love & 0.41 & 0.001 \\
\hline Faith and hope & 0.55 & 0.001 \\
\hline Meaningful & 0.28 & 0.001 \\
\hline Membership & 0.19 & 0.026 \\
\hline Organizational commitment & 0.63 & 0.001 \\
\hline Function & 0.74 & 0.001 \\
\hline Spiritual leadership & 0.44 & 0.001 \\
\hline
\end{tabular}

The results of Table (3) show that between empowerment with perspective (0.35), love of altruism $(0.41)$ and faith and hope (0.55), significance (0.28), membership (0.19), Organizational commitment (0.63), performance (0.74) and spiritual leadership (0.44) There is a positive and significant relationship at $99 \%$ confidence level $(\mathrm{P}<0.05)$.

In the present study, confirmatory factor analysis (CFA) was used to evaluate and evaluate the measurement models. Spiritual leadership and empowerment are the two main scales of the model, which after fitting in Amos software, its fitting indicators are reported in Table (4). It should be noted that in order for measurement models to be validated, firstly, their indices must show a suitable fit and secondly, the values of standard coefficients of factor loads must be desirable (more than $0.5)$ and significant.

Table 4. Fit indicators for each of the measurement models

\begin{tabular}{|c|c|c|c|}
\hline Index & Optimum rate & $\begin{array}{l}\text { Spiritual } \\
\text { leadership }\end{array}$ & $\begin{array}{l}\text { Empower- } \\
\text { ment }\end{array}$ \\
\hline $\mathrm{X} 2 / \mathrm{df}$ & 3 and less & 1.61 & 1.49 \\
\hline RMR & About zero & 0.041 & 0.014 \\
\hline GFI & 0.9 and more & 0.921 & 0.900 \\
\hline
\end{tabular}

\begin{tabular}{|l|l|l|l|}
\hline AGFI & 0.9 and more & 0.945 & 0.925 \\
\hline NFI & 0.9 and more & 0.914 & 0.919 \\
\hline RFI & 0.9 and more & 0.931 & 0.945 \\
\hline IFI & 0.9 and more & 0.959 & 0.922 \\
\hline TLI & 0.9 and more & 0.924 & 0.931 \\
\hline CFI & 0.9 and more & 0.921 & 0.900 \\
\hline PRATIO & 0.5 and more & 0.560 & 0.521 \\
\hline PNFI & 0.5 and more & 0.554 & 0.733 \\
\hline PCFI & 0.5 and more & 0.685 & 0.738 \\
\hline RMSEA & Less than 0.08 & 0.001 & 0.078 \\
\hline
\end{tabular}

The results of confirmatory factor analysis of Table (4) showed that both measurement models have a good fit because the value of $\chi^{2} / \mathrm{df}$ (chisquare divided by the degree of freedom) is less than 3 and the value of RMSEA is less than 0.08, GFI and AGFI values and NFI is greater than 0.9 and economical indices (PNFI and PCFI) are greater than 0.5 and the significance level of factor loads is less than $5 \%$, which indicates the significance of the items in the measurement models (26).

The extracted mean variance index (AVE) was used to assess convergent validity and the combined reliability index (CR) and Cronbach's alpha were used to measure reliability (Table 5). Researchers have found a value of 0.5 or higher for AVE to be 0.6 or higher for CR and a value above 0.7 for Cronbach's alpha (27).

Table 5. Convergent validity results and composite reliability

\begin{tabular}{|l|l|l|l|}
\hline Variables & AVE & \multicolumn{1}{l|}{ CR } & Cronbach's $\boldsymbol{\alpha}$ \\
\hline Spiritual leadership & 0.605 & 0.915 & 0.860 \\
\hline Empowerment & 0.621 & 0.867 & 0.896 \\
\hline
\end{tabular}

To measure divergent validity, the mean of the extracted variances (AVE) is derived and the obtained numbers are compared with the correlation value between the structures, which should be greater than the correlation value between the structures. Table (6) shows the root of the convergent validity values in the original diameter of the matrix. 
Table 6. Results of divergent validity by Fornell and Larcker method

\begin{tabular}{|c|c|c|}
\hline & Spiritual leadership & Empowerment \\
\hline Spiritual leadership & $\sqrt{A V E}=0.778$ & \\
\hline Empowerment & $(\mathrm{r}=0.44)$ & $\sqrt{A V E}=0.778$ \\
\hline
\end{tabular}

The results of table (6) showed that the root mean of the extracted variances (AVE) in the two scales of spiritual leadership (0.778) and empowerment $(0.788)$ is higher than the correlation coefficient between them (0.44). Therefore, both scales have an acceptable level of divergent validity.
Structural equation modeling has been used to fit the research model. Structural equation modeling helps the researcher to test and evaluate a theoretical model consisting of different and diverse components, both in general and in part (27). Figure (1) shows the fitted structural model.

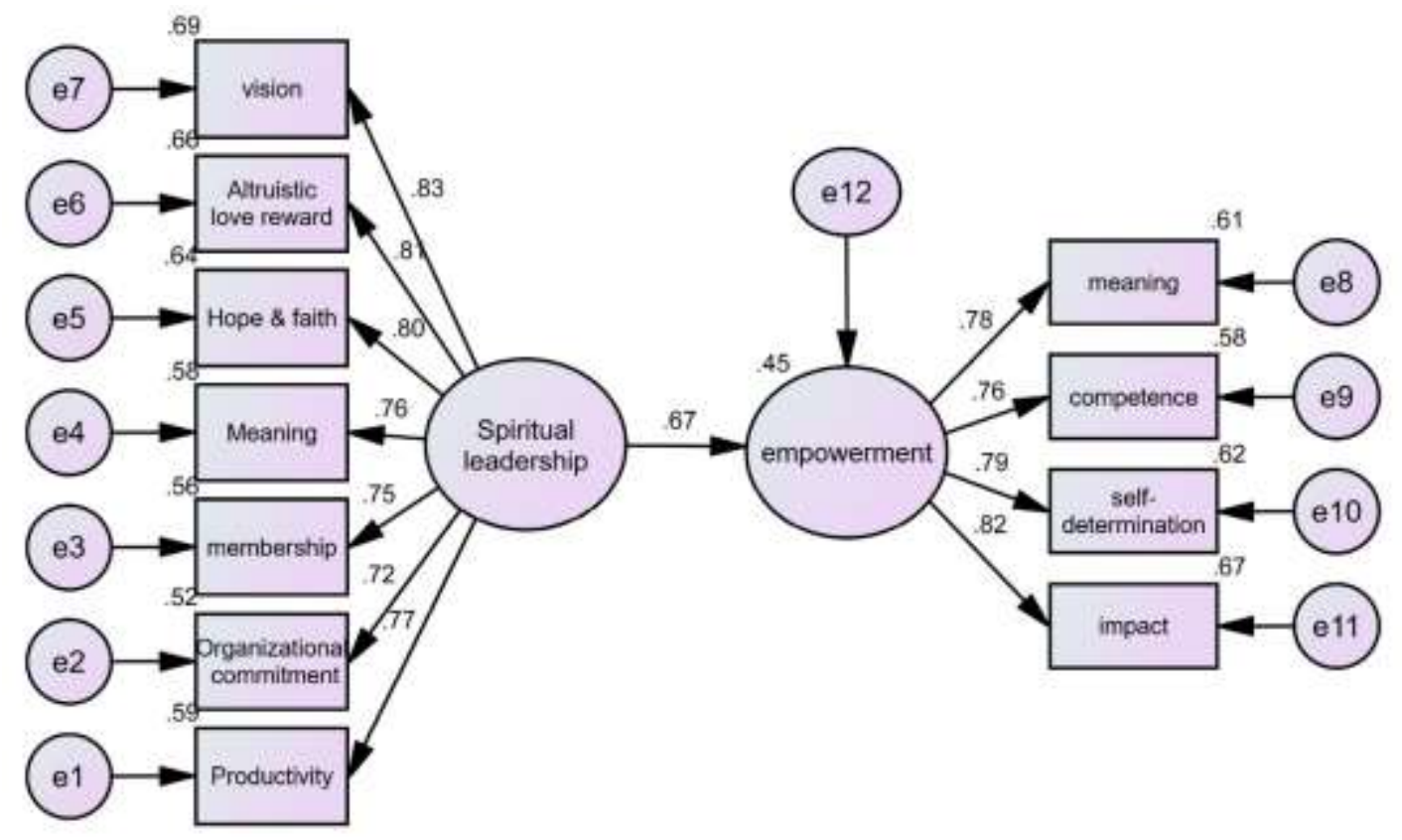

Figure 1. Fitted structural model

Findings in the structural model (Figure 1) show that the value of the coefficient of determination (R2) of the empowerment variable is equal to 0.45 . In other words, $45 \%$ of the variance of the empowerment variable is explained by the spiritual leadership variable. Other findings show that the factor load of the components in two scales is more than 0.7 , which shows that the components explain spiritual leadership and empowerment well. Table (7) shows the fitness indicators of the model.

Table 7. Fitness indicators of the research model

\begin{tabular}{|c|c|c|c|c|c|c|c|}
\hline $\begin{array}{c}\text { Fitness indica- } \\
\text { tors }\end{array}$ & $\chi 2$ 2/df & RMSEA & CFI & TLI & IFI & GFI & AGFI \\
\hline & 1.39 & 0.042 & 0.917 & 0.955 & 0.934 & 0.941 & 0.938 \\
\hline Acceptable rate & Less than3 & $<0.08$ & $>0.9$ & $>0.9$ & $>0.9$ & $>0.9$ & $>0.8$ \\
\hline
\end{tabular}


Fitting indices in Table (7) show that df. $\chi 2$ is less than 3 and RMSEA is less than 0.05. CFI, TLI, IFI, GFI and AGFI indices are all greater than 0.9. Due to the desirability of the fit indices, the structural model of the research is approved.

\section{Discussion}

One of the main elements of universities are faculty members. They can facilitate or slow down the growth and development of the university. Empowerment of professors is an important factor in achieving these goals. Some studies have shown that teacher empowerment is related to the pattern of spiritual leadership. Therefore, the purpose of this study was to predict the empowerment of faculty members of Farhangian University based on spiritual leadership.

Findings showed that there is a significant relationship between faculty empowerment and spiritual leadership. In total, spiritual leadership is able to predict $45 \%$ of the variance of the criterion variable, i.e. empowerment of Farhangian University faculty members.

Some researchers have also concluded that spiritual leadership has an effect on employee empowerment (14). In a study, researchers concluded that the dimensions of spiritual leadership (relationship with God, relationship with others, relationship with self, and work motivation) are related to organizational empowerment (17). Other researchers have concluded that spiritual leadership has an effect on employee empowerment and performance $(18,19)$. In other studies, researchers have concluded in similar results that the pattern of spiritual leadership has an effect on organizational empowerment and work performance of human resources $(13,21-23)$.

Communication approach in employee empowerment believed that empowerment is a set of managerial activities that give employees power, control and authority (6). In other words, this view sees empowerment as an effort to increase the levels of employee participation in the decision-making process, which encourages employees to participate more actively throughout the organization
(7). Based on this, it can be said that spiritual leadership style is a kind of management model that can give value and value to employees as a training staff. In fact, the scientific environment of the university requires a reciprocal relationship between management and staff. The higher the level of these relationships, the more flourishing professors can be expected to flourish. The pattern of spiritual leadership gives employees meaningful work, independence in professional duties, competence to be effective, and so on. In the scientific environment, when the leadership of the university is based on clear and ethical relations, the members of the faculty will reach a sense of value and effectiveness (16). In fact, spiritual leadership, by creating relationships and professional independence of duties, provides the ground for professors to know the limits of their duties accurately, and this can empower them in the fields of science and education, creativity, reduce educational costs, increase social cohesion and increase problem solving. And challenges within the university organization.

Based on the psychological empowerment approach, it can be said that when teachers experience a sense of usefulness and value, this can make their activities dynamic. Given that human needs are hierarchical, that is, the need for respect, acceptance by others and gaining respect from others is at a high level (28). Therefore, spiritual leadership makes employees understand the true meaning of their job and care about their duties. It also makes them feel that their job is important to the organization and other partners. This positive assessment and perception of employees can help improve the work environment and their abilities. Therefore, it can be said that the model of spiritual leadership that emphasizes the ethics and privacy of employees makes a person find a positive perception of his position in the eyes of others. This positive attitude and perception is a factor for growth and ultimately empowerment.

The results showed a significant relationship between spiritual leadership and empowerment of faculty members of Farhangian University. Nevertheless, research results should be viewed with 
caution. This study was a case study in Farhangian universities of Isfahan province and to generalize the results, there is a need for studies at a larger level, which was not possible for the researcher due to financial constraints. Another limitation of the research was the quantitative research approach, which could not be studied with a combined approach. Because the research period in the early global pandemic conditions of the corona virus was that universities did not allow face-toface interviews to comply with health protocols, but it was possible to complete questionnaires. Therefore, future researchers are suggested to study the spiritual leadership and empowerment of faculty members in the future with a combined approach (qualitative and quantitative). Also, the study should be done at a larger level to provide more confidence in the generalization of the results. Another suggestion is to select some professors from Farhangian University as qualified teachers so that they can better understand Farhangian University. It is suggested that the selection of the deans of Farhangian University be chosen from among the professors themselves and not from outside in order to provide the ground for more sincere cooperation as one of the important components of empowerment among the faculty members of the university.

\section{Conclusion}

Spiritual leadership is a relatively new topic in the field of management and leadership of organizations. Studies of spiritual leadership have shown that the more spiritual leadership and its dimensions are used in organizations, the better the ability and performance of employees can be witnessed. The present study also showed that spiritual leadership is effective on empowering university professors and its dimensions can predict the psychological empowerment of faculty members. Therefore, more attention should be paid to spiritual leadership in universities, especially Farhangian University, the end product of which is teacher training.

\section{Ethical Consideration}

Ethical issues (such as plagiarism, conscious satisfaction, misleading, making and or forging data, publishing or sending to two places, redundancy and etc.) have been fully considered by the writers.

\section{Conflict of Interest}

The authors declare that there is no conflict of interests.

\section{Acknowledgement}

All the educated and valuable professors who willingly participated in the research and completed the questionnaires despite the challenge of coronary heart disease are appreciated.

\section{References}

1. Caruso DR, Fleming K, Spector ED (2014). Emotional intelligence and leadership. In: Conceptions of leadership. Palgrave Macmillan, New York.

2. Vazquez J L, Aza C L, Lanero A (2014). Responsible human resources management in the University - a view of Spanish students. Human Resources Management and Ergonomics, 8(1):118-128.

3. Giorgidze L (2010). Study of employee empowerment and job satisfaction of university staff in a TQM perspective: implications for higher education managers. Quality Issues and Insights in the 21st Century, 5(1): 1-14.

4. Damar A, Eskiler E (2017). The impact of spiritual leadership on empowerment and work procrastination. SHS Web of Conferences, New York. DOI: https://doi.org/10.1051/SHSCONF\%2F20173701056

5. Irannejad Parizi M, SasanGohar P (2014). Organization and management from theory to practice. Iran Higher Institute of Banking, Tehran/Iran. (In Persian).

6. Bennis WG, Townsend R (2005). Reinventing leadership: Strategies to empower the onganization. Harper Collins, USA.

7. Niehoff BP, Moorman RH, Blakely G, Fuller J (2001). The influence of empowerment and job enrichment on employee loyalty in a downsizing environment. Group \& Organization Management, 26(1): 93-113. DOI: http://dx.doi.org/10.1177/1059601101261006

8. Spreitzer GM (1995). Psychological empowerment in the workplace: Dimensions, measurement, and validation. Academy of Management Journal, 38(5): 1442-1465. DOI: https://doi.org/10.5465/256865 
9. Karnama A, Sheikhpour M (2015). Investigating the relationship between leadership style and employees' empowerment. Indian Journal of Fundamental and Applied Life Sciences, 5(1): 5493-5499.

10. Singh SK, Gupta S, Busso D, Kamboj S (2019). Top management knowledge value, knowledge sharing practices, open innovation and organizational performance. Journal of Business Researh, 1-11.

11. Reave L (2005). Spiritual values and practices related to leadership effectiveness. The Leadership Quarterb, 16(5): 655-687. DOI: https://doi.org/10.1016/i.leaqua.2005.07.003

12. Smith G, Mino M, Brashen H (2018). Spiritual leadership: a guide to a leadership style that embraces multiple perspectives. Joumal of Instructional Research, 7: 80-89. DOI: https://doi.org/10.9743/JIR.2018.7

13. Yang M, Fry LW (2018). The role of spiritual leadership in reducing healthcare worker burnout. Journal of Management, Spirituality \& Religion, 15(4): 305-324. DOI: https://doi.org/10.1080/14766086.2018.1482562

14. Nasr Esfahani A, Sobhani M, Khazaei Pool J, Amani M (2015). Analysis of the effect of spiritual leadership and its consequences on organizational performance by using a balanced scorecard in small and medium enterprises in Isfahan. Scientific Journal of Organizational Culture Management, 13(1): 247-265. (In Persian). DOR: https://dx.doi.org/10.22059/jomc.2015.53302

15. Der Janinieh DN (2011). Empowering behavior and leader fairness and integrity: Studying perceptions of ethical leader behavior from a levels-of-analysis perspective. European Journal of Work and Organizational Psychology, 18(2): 199-230.

DOI: https://doi.org/10.1080/13594320802362688

16. Fry LW, Hannah ST (2011). Impact of spiritual leadership on unit performance. The Leadership Quarterly, 25(5): $1-12$.

17. Ghaffari R, Rostamniya Y (2017). Organizational social inertia and laziness; dysfunctions of the bureaucratic organizational culture. Journal of Public Administration, 9(2): 307-332. (In Persian)

18. Samiee Zafarghani M (2016). The relationship between spiritual leadership in organizations and personnel empowerment. Management in Training Organizations, 5 (1): 93 110. (In Persian)
19. Miri A, Aghazadeh F, Nouri R (2014). Identifying the optimal level of organizational spirituality in relation to maximizing the performance of Qazvin governor's staff. Quarterly Journal of Development and Transformation Management. (Special Issue):101-108.

20. Shabani Bahar G, Farahani A, Qara M.A, Siavashi M (2013). The design of the structural model of the effect of spiritual leadership on psychological empowerment in faculty members of physical education and sports sciences faculties. New Trend in Sport Management, 1 (3): 87103 (In Persian).

21. Wang M, Guo T, Ni Y, Shang S and Tang Z (2019). The effect of spiritual leadership on employee effectiveness: an intrinsic motivation perspective. Front. Psychol, 9:1-11. DOI: https://doi.org/10.3389/fpsyg.2018.02627

22. Sharifpour Y, Sukati I, Mazhari MY, Mohammadi MA, Salavatihesari E, Alizadeh M (2013). Investigation of the relationship spiritual leadership of managers with cognitive empowerment of employees (case study: employees and managers the customs of the west of Iran). Eumpean Journal of Scientific Research, 116 (3): 411-419.

23. Walumbwa Fo, Hartnell CA, Oke A (2010). Servant leadership, procedural justice climate, service climate, employee attitudes, and organizational citizenship behavior: a cross-level investigation. Journal of Applied Psycbology, 95(3): 517. DOI: http://dx.doi.org/10.1037/a0018867

24. Luckcock T (2011). Spirited leadership and the struggle for the soul of head teachers: Differentiating and balancing nine types of engagement. Educational Management Administration \& Leadership, 38(4): 405-422. DOI: 10.1177/1741143210368302

25. Taghizadeh H, Ziraksar Z (2018). The relationship between spiritual leadership in the light of ethical beliefs of employees with organizational adaptability. Ethics in Science and Technology, 13 (1) :65-73 (In Persian).

26. Kalantari K (2009). Structural equation modeling in socio-economic research. Farhang Saba, Tehran/Iran. (In persian)

27. Ghasemi V (2010). Structural equation modeling in social research using Amos graphics. Sociologists Publications, Tehran/Iran. (In Persian)

28. Shahrawat A, Shahrawat R (2017). Application of Maslow's hierarchy of needs in a historical context: Case studies of four prominent figures. Psychology, 8(7): 939. DOI: 10.4236/psych.2017.87061 